Ecografía de tórax utilidad y beneficios para el diagnóstico de patología pulmonar

\title{
Ecografía de tórax utilidad y beneficios para el diagnóstico de patología pulmonar
}

\section{Echography of thorax utility and benefits for the diagnosis of pulmonary pathology}

\section{Utilidade de ultrassonografia de tórax e benefícios para o diagnóstico depatologia pulmonar}

\author{
Jenny R. Cedeño-Chóez ${ }^{\mathrm{I}}$ \\ jenny.ceno@hotmail.com \\ Luis O. Vulgarin-Martínez II \\ luis.vulgarin12@gmail.com \\ María E. Moreno-Medina III \\ dramaria_moreno@hotmail.com
}

Recibido: 17 de mayo de 2019 * Corregido: 15 de junio de 2019* Aceptado: 05 de julio de 2019

I. Diploma Superior en Enfermedades Inmunodeficientes en VIH-SIDA, Magister en Ginecología Infanto Juvenil y Salud Reproductiva del Adolescente, Médico, Universidad de Guayaquil, Guayaquil, Ecuador.

II. Especialista en Cirugía General, Doctor en Medicina y Cirugía, Universidad Católica de Santiago de Guayaquil, Guayaquil, Ecuador.

III. Diploma Superior en Enfermedades Inmunodeficientes en Vih-Sida, Magister en Emergencias Médicas, Médico, Obstetriz, Universidad de Guayaquil, Guayaquil, Ecuador. 


\title{
Resumen
}

La ecografía es una prueba diagnóstica de imagen, basada en los efectos de los ultrasonidos en el organismo. Actualmente, constituye una herramienta básica, prácticamente en todas las especialidades de la medicina y cirugía. Sus numerosas ventajas han contribuido a su uso generalizado, cada vez más frecuente en la práctica clínica diaria. Este tipo de estudio, representa un método de imagen muy dependiente del operador y su aprendizaje requiere, al menos de forma básica, del conocimiento de las bases físicas, la aparatología y las múltiples prestaciones que pueden ofrecer los ecógrafos. Las imágenes ecográficas del tórax, ya sea normal o en presencia de patología, vienen determinadas por la diferente impedancia acústica de los tejidos que lo forman (tejidos blandos, hueso, pleura, aire), que va a permitir identificar algunas estructuras anatómicas y, en otros casos, produce artefactos. La pared torácica aparece como una serie de capas de tejidos blandos de distinta ecogenicidad. La más superficial corresponde a la piel, la cual se visualiza como una capa ecogénica de 1 a $3 \mathrm{~mm}$ de espesor. Inmediatamente inferiores, se identifican la grasa subcutánea y los músculos intercostales, éstos últimos visibles como múltiples estrías ecogénicas sobre una base hipo ecoica, El papel de la ecografía en la evaluación de las enfermedades del tórax es ampliamente reconocido y, tradicionalmente, ha sido en esta patología donde la técnica ha tenido mayor difusión, en especial en la detección del derrame pleural y como guía para la toracocentesis. Es más sensible que la radiografía de tórax convencional, pues detecta derrames pleurales, visualizando hasta $5 \mathrm{ml}$ de líquido. Este estudio, es útil, en la definición de las características del líquido pleural y orientar su etiología, dirigir otros procedimientos, como la biopsia pleural o la tora coscopia, localizar y guiar la punción de masas o engrosamientos pleurales, o en el diagnóstico del neumotórax.

Palabras claves: Ecografía de Tórax; Patología Pulmonar; Líquido Pleural; Prueba Diagnóstica; Derrame Pleural.

\begin{abstract}
Ultrasound is a diagnostic imaging test, based on the effects of ultrasound in the body. Currently, it constitutes a basic tool, practically in all the specialties of medicine and surgery. Its numerous advantages have contributed to its widespread use, increasingly frequent in daily clinical practice. This type of study represents a method of image that is highly dependent on the operator and its learning requires, at least in a basic way, the knowledge of the physical bases, the apparatus and the multiple features that ultrasounds can offer. Ultrasound images of the chest, whether normal or in the presence of pathology, are determined by the different acoustic impedance of the tissues that form it (soft tissues, bone, pleura, air), which will allow identifying some anatomical structures and, in In other cases, it produces artifacts. The chest wall appears as a series of soft tissue layers of different echogenicity. The most superficial corresponds to the skin, which is visualized as an echogenic layer of 1 to $3 \mathrm{~mm}$ thick. Immediately inferior, subcutaneous fat and intercostal muscles are identified, the latter visible as multiple echogenic stretch marks on a hypo echoic basis. The role
\end{abstract}


of ultrasound in the evaluation of chest diseases is widely recognized and, traditionally, has been in this pathology where the technique has been more widespread, especially in the detection of pleural effusion and as a guide for thoracentesis. It is more sensitive than conventional chest radiography, as it detects pleural effusions, visualizing up to $5 \mathrm{ml}$ of fluid. This study is useful, in defining the characteristics of the pleural fluid and guiding its etiology, directing other procedures, such as pleural biopsy or coscopy torah, locating and guiding mass puncture or pleural thickening, or in the diagnosis of pneumothorax. .

Key words: Chest Ultrasound - Pulmonary Pathology - Pleural Liquid - Diagnostic Test Pleural effusion.

\section{Resumo}

O ultra-som é um teste de diagnóstico por imagem, baseado nos efeitos do ultra-som no corpo. Atualmente, constitui uma ferramenta básica, praticamente em todas as especialidades da medicina e cirurgia. Suas inúmeras vantagens contribuíram para o seu uso disseminado, cada vez mais freqüente na prática clínica diária. Esse tipo de estudo representa um método de imagem altamente dependente do operador e seu aprendizado requer, pelo menos de maneira básica, o conhecimento das bases físicas, do aparato e das múltiplas características que os ultrassons podem oferecer. As imagens de ultrassonografia do tórax, sejam normais ou na presença de patologia, são determinadas pelas diferentes impedâncias acústicas dos tecidos que a formam (tecidos moles, osso, pleura, ar), o que permitirá identificar algumas estruturas anatômicas e, em Em outros casos, produz artefatos. A parede torácica aparece como uma série de camadas de tecidos moles de diferente ecogenicidade. $\mathrm{O}$ mais superficial corresponde à pele, que é visualizada como uma camada ecogênica de $1 \mathrm{a} 3 \mathrm{~mm}$ de espessura. Identificam-se imediatamente tecido adiposo subcutâneo inferior e músculos intercostais, estes últimos visíveis como múltiplas estrias ecogênicas em base hipoecoica.O papel do ultrassom na avaliação de doenças torácicas é amplamente reconhecido e, tradicionalmente, tem sido patologia onde a técnica tem sido mais difundida, especialmente na detecção de derrame pleural e como guia para toracocentese. É mais sensível que a radiografia convencional de tórax, pois detecta efusões pleurais, visualizando até $5 \mathrm{ml}$ de líquido. Este estudo é útil para definir as características do líquido pleural e orientar sua etiologia, direcionando outros procedimentos, como a biópsia pleural ou a coscopia da torá, localizando e orientando a punção em massa ou o espessamento pleural ou no diagnóstico de pneumotórax. .

Palavras-chave: Ultrassonografia de tórax; Patologia Pulmonar; Líquido pleural; Teste de Diagnóstico; Derrame pleural. 


\section{Introducción.}

La ecografía es un excelente método diagnóstico que puede ser utilizado de manera regular o, en casos de urgencia por especialistas y médicos cirujanos en general. Entre sus ventajas se destacan su accesibilidad, confiabilidad y no invasividad, generalmente es de rápida realización y bajo costo, su fácil acceso (equipo portátil), permite un mejor seguimiento clínico. En la actualidad, la ecografía es utilizada como método de estudio inicial, para el diagnóstico específico tanto en la patología traumática como no traumática. A partir de ella se arriba a un diagnóstico u orienta hacia métodos diagnósticos a seguir, lo que lleva a determinar en gran parte los casos que ameritan tomar una decisión terapéutica definitiva. (Cerrat, 2016).

La ecografía ha tenido un desarrollo explosivo durante los últimos veinte años debido a una disminución de los costos y a una progresiva mejoría en su resolución. Esta mayor disponibilidad de equipos de buena calidad, con un aparato portátil y no invasivo ha tenido como consecuencia que muchos médicos, de distintas especialidades, se hayan ido familiarizando con este método diagnóstico. La gran utilidad de la ecografía en el manejo de pacientes traumatizados y su uso en el intra operatorio ha incentivado a cirujanos a capacitarse en su uso. (Cerrat 2016)

La ecografía, representa un método diagnóstico que utiliza la energía mecánica de las ondas ultrasónicas y aprovecha las propiedades acústicas de la materia para generar imágenes corporales en escala de grises y así representar parámetros de flujo. Al hacer una ecografía, mediante el transductor se aplica un haz de ultrasonidos sobre el paciente. Este haz se introduce en el organismo y, a medida que profundiza y atraviesa los diferentes tejidos, produciendo ecos que el transductor recoge y el ecógrafo los transforma en imágenes. La imagen que habitualmente es usada en el 
estudio ecográfico es el modo B, que se refiere a la imagen bidimensional en escala de grises en tiempo real. (Cerrat 2016).

Figura 1: En el modo B cada punto de la pantalla tiene un brillo proporcional al nivel de ecos. Si no hay ecos el punto es negro. Si hay gran intensidad de ecos el punto será blanco. Entre ambos extremos se obtendrá la gama de grises.

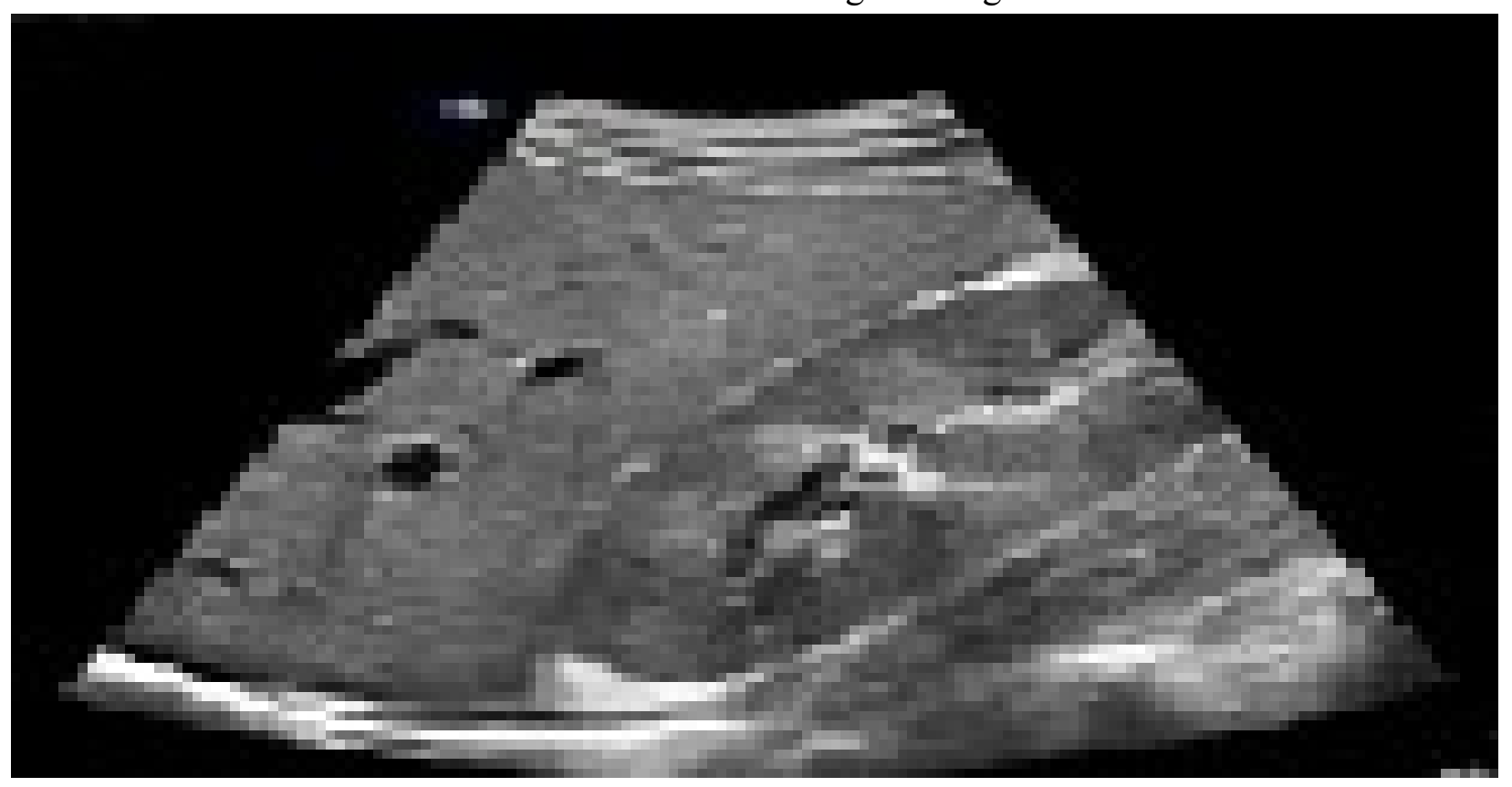

Fuente: (Cerrat 2016).

La orientación habitual de la imagen es aquella en la que la parte superior en la pantalla corresponde a la superficie donde se aplica el transductor. La zona inferior son los planos profundos hasta donde llega el sonido y los laterales bordes del transductor. Para facilitar la orientación, uno de estos bordes tiene siempre una señal o marca que coincide en la pantalla con una señal en un lado de la imagen ecográfica.

Tal señalamiento permite añadir que, el desarrollo tecnológico ha llevado a la comercialización de multiplicidad de ecógrafos; destacándose entre ellos: ecógrafos más pequeños y portátiles, con excelentes prestaciones, que destacan la mejora de la calidad y resolución de las 
imágenes obtenidas y la mayor accesibilidad a la técnica, lo cual ha contribuido a que la mayoría de especialidades médicas y quirúrgicas hayan incorporado la ecografía como una nueva herramienta en su práctica clínica diaria.

A partir de las referencias básicas de los planos principales de estudio en el diagnóstico por imagen (longitudinal o sagital, axial o transversal, y coronal), la ecografía permite infinitos planos de exploración, dado que se puede girar y realizar barridos en los tres ejes del espacio, generando que la generación de múltiples imágenes por segundo produzca el efecto del tiempo real. Según (Canott, 2015):

En los últimos años se han descrito numerosas aplicaciones de la ecografía en el estudio de diversas enfermedades del tórax que afectan no sólo a la pleura, sino también al pulmón, pared torácica o diafragma. Comparada con otras pruebas de imagen, la ecografía presenta importantes ventajas, entre las que se incluyen la ausencia de radiaciones ionizantes y la obtención de imágenes en tiempo real, además de su portabilidad y bajo coste. (p.87)

Según lo descrito, la ecografía ha limitado su uso a la localización de derrames pleurales pequeños o loculados, o como guía para la inserción de drenajes torácicos en empiemas. Sin embargo, en los últimos 20 años se ha observado un importante desarrollo de la ecografía torácica, la cual fue hecha evidente, posterior a 1995, cuando Lichtenstein publicara un trabajo que demostraba la utilidad de la ecografía en el diagnóstico de neumotórax, lo que ha generado el surgimiento de numerosas publicaciones, las cuales han descrito cada vez más aplicaciones de la técnica en el estudio y manejo de diferentes patologías del pulmón, pleura, pared torácica y diafragma. (Garnerd, 2016). 
En virtud de esto, hoy día se considera la ecografía como una prueba de imagen básica en la medicina respiratoria. Este método diagnóstico comparado con otras pruebas de imagen de uso habitual en patología torácica, como la radiografía o la tomografía computarizada (TC), la ecografía ofrece numerosas ventajas, destacándose entre ellas, las siguientes:

- Permite una evaluación dinámica del espacio pleural y el pulmón, así como proporciona imágenes en tiempo real.

- No expone al paciente a radiaciones ionizantes, por lo que se considera una técnica segura. Esto es especialmente importante para personas más susceptibles a los efectos adversos de la radiación, como niños y mujeres embarazadas.

- Por otra parte, hace que la exploración puede repetirse tras intervenciones terapéuticas o como monitorización de diversas enfermedades.

- La disponibilidad de equipos portátiles permite su realización a la cabecera del paciente. Este aspecto puede resultar crucial en aquellos de difícil movilización, como los ingresados en unidades de cuidados intensivos, o en medios donde exista difícil acceso a otras pruebas de imagen.

- En comparación con otras técnicas, el coste de la ecografía es bajo. (Betroit 2017).

A todas estas ventajas se añaden, actualmente, avances tecnológicos, como el desarrollo, cada vez mayor, de la ecografía de contraste, el uso de armónicos tisulares, mejoras en la ecografía Doppler y la optimización de imágenes en escala de grises. La principal limitación de la ecografía es su dependencia del examinador, de sus conocimientos y experiencia en la técnica. Por ello, resultan esenciales el entrenamiento en la adquisición e interpretación de imágenes y el aprendizaje de los diferentes patrones ecográficos. (Garnerd 2016) 
Por último, debe tenerse en cuenta que la ecografía aporta información complementaria a otras pruebas de imagen y, obviamente, a una correcta anamnesis y exploración clínica. Por lo tanto, en la práctica clínica la ecografía ha de ser integrada junto a la evaluación de datos clínicos y otros métodos de imagen. En este contexto, la ecografía pulmonar, gracias a su portabilidad, se convierte en una técnica alternativa en determinadas situaciones, con la ventaja de realizarse a la cabecera de los pacientes, ser fácilmente reproducible y no administrar radiaciones ionizantes.

En la ecografía pulmonar, las costillas, la columna vertebral y el aire del pulmón actúan como barreras para los ultrasonidos, y provocan artefactos que deben ser reconocidos e interpretados para un correcto diagnóstico. No obstante, las enfermedades intra torácicas y la existencia de líquido en el espacio pleural, así como la consolidación o atelectasia en el pulmón proporcionan suficiente ventana ecográfica para una correcta evaluación. (Garnerd 2016)

En términos generales, la ecografía se ha revelado como una técnica clínica de imagen de gran utilidad en los pacientes con afecciones de tórax o en situación crítica. Dos han sido las características que la han convertido en un procedimiento de primera línea en la exploración de los enfermos graves. La primera: es la ausencia de emisión de radiaciones, lo que la hace especialmente apropiada para determinar dos grupos (niños y mujeres embarazadas), además permite la repetición de pruebas tantas veces como sea necesaria, sin incrementar el riesgo. La segunda: ventaja es la portabilidad que tiene de ser dirigida a la cabecera del paciente; aspecto éste especialmente importante, por lo que supone de evitar riesgos en los traslados.

De todas las áreas de exploración, las que se consideran esenciales en el currículo de los intensivistas son la ecocardiografía (básica y avanzada), la ecografía vascular, tanto para la cateterización venosa central como para la detección de trombosis venosa, y la ecografía pulmonar 
(denominada por algunos grupos pleuro pulmonar). En el caso de los traumatizados, se ha desarrollado una combinación simple de varias de estas denominada focus edassesment with sonograph y for trauma (FAST).

Tradicionalmente, el abordaje diagnóstico del tórax en el paciente crítico se ha basado en la radiografía simple antero posterior, que es esencial en la evaluación de los múltiples dispositivos asociados al tratamiento de estos pacientes (tubo traqueal, catéteres venosos centrales, etc.), pero que presenta grandes limitaciones en la precisión diagnóstica de la enfermedad pleuro pulmonar. La introducción de la tomografía axial computarizada (TAC) resolvió en gran medida este problema con una resolución cada vez mejor, pero con el inconveniente de las dosis de radiación y sobre todo, el inevitable traslado fuera de la unidad de cuidados intensivos. (Betroit, 2017). No obstante, en la actualidad la ecografía de tórax ha venido a sustituir todas estas modalidades clínicas, para dar paso a una técnica diagnóstica de mayor precisión y exactitud.

\section{Tipo de Investigación}

Dentro de toda práctica investigativa, se precisan acciones de carácter metodológico mediante las cuales, se logra conocer y proyectar los eventos posibles que la determinan, así como las características que hacen del acto científico un proceso interactivo ajustado a una realidad posible de ser interpretada. En este sentido, se puede decir, que la presente investigación corresponde al tipo documental, definido por (Dávila, 2012), "se ocupa del estudio de problemas planteados a nivel teórico, la información requerida para abordarlos se encuentra básicamente en materiales impresos, audiovisuales y /o electrónicos". (p.41). 
En consideración a esta definición, la orientación metodológica permitió la oportunidad de cumplir con una serie de actividades inherentes a la revisión y lectura de diversos documentos donde se encontraron ideas explicitas relacionadas con los tópicos encargados de identificar a cada característica insertada en el estudio. Por lo tanto, se realizaron continuas interpretaciones con el claro propósito de revisar aquellas apreciaciones o investigaciones propuestas por diferentes investigadores, para luego dar la respectiva argumentación a los planteamientos, en función a las necesidades encontradas en la indagación.

\section{Fuentes Documentales}

El análisis correspondiente a las características que predomina en el tema seleccionado, llevan a incluir diferentes fuentes documentales encargadas de darle el respectivo apoyo y en ese sentido cumplir con la valoración de los hechos a fin de generar nuevos criterios que sirven de referencia a otros procesos investigativos. Para (Arias, 2010), las fuentes documentales incorporadas en la investigación documental o bibliográfica, "representa la suma de materiales sistemáticos que son revisados en forma rigurosa y profunda para llegar a un análisis del fenómeno". (p.41). Por lo tanto, se procedió a cumplir con la realización de una lectura previa determinada por encontrar aquellos aspectos estrechamente vinculados con el análisis de la "Ecografía de Tórax: utilidad y beneficios para el diagnóstico de Patología Pulmonar" para luego explicar mediante un desarrollo las respectivas apreciaciones generales de importancia.

\section{Técnicas para la Recolección de la Información}

La conducción de la investigación para ser realizada en función a las particularidades que determinan a los estudios documentales, tiene como fin el desarrollo de un conjunto de acciones 
encargadas de llevar a la selección de técnicas estrechamente vinculadas con las características del estudio. En tal sentido, (Arias Ob cit) refiere, que es "una técnica particular para aportar ayuda a los procedimientos de selección de las ideas primarias y secundarias". (p. 71).

Por ello, se procedió a la utilización del subrayado, resúmenes, fichaje, como parte básica para la revisión y selección de los documentos que presentan el contenido teórico. Es decir, que mediante su aplicación de estas técnicas se pudo llegar a recoger informaciones en cuanto a la revisión bibliográfica de los diversos elementos encargados de orientar el proceso de investigación. Tal como lo expresa, (Arias Ob cit) "las técnicas documentales proporcionan las herramientas esenciales y determinantes para responder a los objetivos formulados y llegar a resultados efectivos" (p. 58). Es decir, para responder con eficiencia a las necesidades investigativas, se introdujeron como técnica de recolección el método inductivo, que hizo posible llevar a cabo una valoración de los hechos de forma particular para llegar a la explicación desde una visión general.

Asimismo, se emplearon las técnicas de análisis de información para la realización de la investigación que fue ejecutada bajo la dinámica de aplicar diversos elementos encargados de determinar el camino a recorrer por el estudio, según, (Arias, Ob cit) las técnicas de procesamiento de datos en los estudios documentales "son las encargadas de ofrecer al investigador la visión o pasos que debe cumplir durante su ejercicio, cada una de ellas debe estar en correspondencia con el nivel a emplear" (p. 123). Esto indica, que para llevar a cabo el procesamiento de los datos obtenidos, es necesario establecer las técnicas que serán seleccionadas, destacándose en este caso, de manera particular: fichas de resumen, textual, registros descriptivos entre otros, los mismos se deben ajustar al nivel que ha sido seleccionado. 


\section{Resultados}

\section{TÉCNICA DE EXAMEN}

El equipo de ecografía necesario para la realización de la técnica solo precisa de imagen bidimensional y en modo $\mathrm{M}$, pero actualmente casi todos los equipos modernos están dotados de otras posibilidades (Doppler, color, armónicos, etc.). Más importante es la disponibilidad de sondas multi frecuencia o de varios tipos de sonda. Las sondas de frecuencias entre 3,5-5 MHz, utilizadas para la exploración abdominal y cardiaca, proporcionan una adecuada visualización de los planos profundos, y permiten la caracterización de las consolidaciones y el derrame pleural.

Para las estructuras más superficiales, es decir, la pleura y los signos y los artefactos que se generan de ella, las sondas de frecuencia superior a $5 \mathrm{MHz}$ proporcionan mucha mejor resolución. Estas sondas se emplean, además, para el estudio vascular, lo que nos sirve de complemento en el diagnóstico de la trombosis venosa profunda. La forma de la sonda utilizada (lineal, convexa o sectorial) también dependerá' de la zona a estudiar, y será convexa si el espacio intercostal es estrecho, para evitar la interferencia acústica que producen las costillas.

Los transductores sectoriales no son, en general, adecuados para el examen del espacio pleural por vía intercostal directa, ya que presenta una visión muy estrecha en los campos cercanos y el espacio pleural se identifica mal por los artefactos. En los pacientes críticos, la exploración se realiza en la posición de decúbito supino, que permite un fácil abordaje antero lateral. Cada grupo de investigadores ha desarrollado una sistemática de exploración propia, a veces excesivamente prolija y compleja. 
La exploración comenzaría por la zona anterosuperior y acabaría por la latero inferior, con cortes longitudinales y transversales. A veces es necesario el estudio de las zonas dorsales, para lo que es precisa una ligera inclinación del enfermo, que se logra exclusivamente con una leve aducción del brazo ipso lateral. Aunque algunos expertos afirman que puede hacerse una exploración completa en unos $3 \mathrm{~min}$, nuestra experiencia es que son necesarios entre 5-10 minutos, según la complejidad de los hallazgos.

\section{PATRONES ECOGRÁFICOS}

\section{Imagen Normal}

Al situar el transductor lineal en sentido longitudinal perpendicular a los espacios intercostales se visualizan cerca de los bordes laterales de la pantalla 2 interfaces ecogénicas redondeadas con una marcada sombra acústica que corresponde a las costillas. Aproximadamente a medio centímetro por debajo del inicio de estas se sitúa una línea hiper ecogénica horizontal que representa la pleura.

Con transductores de alta frecuencia y gran resolución a poca profundidad se pueden observar las 2 capas, parietal y pleural, de unos $2 \mathrm{~mm}$ de anchura y de aspecto regular, separadas entre sí por el espacio pleural $(0,3 \mathrm{~mm})$. Sin embargo, con los transductores que se emplean habitualmente (de o5 MHz), la línea es única y representa la superficie de unión pleuro pulmonar. En conjunto, el borde superior de las sombras de las costillas y la línea pleural componen una imagen que semeja el perfil de un murciélago, y por esto ha recibido la denominación bat sign. (Bustiet 2017) 
El pulmón aireado subyacente a la pleura es una inter fase altamente reflectante que bloquea la penetración de los haces de ultrasonidos. El patrón del pulmón normal representa, por tanto, un artefacto por reverberación con múltiples ecos de una intensidad media, de aspecto moteado. La principal característica que hay que observar es la presencia de deslizamiento o signo del planeo en la superficie de unión pleuro pulmonar, que ocurre obligatoriamente con la insuflación y el vaciado pulmonar durante las fases respiratorias.

Si se aplica el modo M, se distinguen 2 zonas bien diferenciadas, que configuran el signo de la orilla (seashore sign): la parte superior, que corresponde a la pared torácica, formada por líneas horizontales paralelas (el mar), y la parte inferior, desde la pleura, de aspecto granulado, como arena de playa (sandy beach). También en modo real (bidimensional) se puede visualizar el movimiento de ambos hemi diafragmas y cómo en inspiración el pulmón se desplaza caudalmente, y aparece en ocasiones como un velo o una cortina.

\section{Consolidación pulmonar}

Para poder diagnosticar una consolidación pulmonar previamente se deben dar 2 requisitos. El primero es su localización intra torácica. Para esto en las zonas basales es importante localizar el diafragma, ya que en supino y con pérdida de volumen, tanto el hígado como el bazo pueden estar localizados más cranealmente y, por su aspecto, confundirse con una consolidación. El segundo es que exista contacto con la pleura para que los ultrasonidos la vean. Esta condición se cumple en la inmensa mayoría de las consolidaciones (90\%), pero a veces hay que ser exhaustivo en la exploración de todas las áreas, especialmente las dorsales, para que no pasen desapercibidas. 
En la consolidación pulmonar los espacios aéreos están rellenos de liquido o células inflamatorias, por lo que, en esta situación, el pulmón aireado que es altamente reflexógeno se convierte en una masa sólida, densa y con buena transmisión sónica. El pulmón consolidado es hipo ecogénico en comparación con el pulmón aireado y también, generalmente, con respecto al hígado y al bazo por su alto contenido acuoso. Los criterios diagnósticos de la presencia de una consolidación pulmonar son los siguientes:

- Patrón tisular: similar al del tejido de órganos sólidos como el hígado. Es el único criterio imprescindible, el resto se consideran adicionales.

- Limites anatómicos: mientras que el borde superficial correspondiente a la pleura es regular, el borde profundo se muestra irregular, salvo que exista una afectación lobar completa o sea una pequeña consolidación sub pleural.

- Ausencia de artefactos (líneas A o B): el reemplazo de aire por otro tipo de material (edema, celularidad) o su ausencia (colapso) impide la formación de los artefactos que dependen de la interacción en la inter fase aire/fluido.

- Ausencia del signo del sinusoide, lo que la distingue de un derrame pleural en aquellos casos en los que presenta una ecogenicidad reducida.

- Presencia de bronco grama aéreo y alveolo grama aéreo, la existencia de aire en las vías aéreas se manifiesta como imágenes hiper ecogénicas puntiformes o lineales, en función de que se corten transversal u horizontalmente. Representan el aire en el interior de los bronquios o alveolos rodeados del pulmón consolidado.

- Visualización de arterias y venas pulmonares intra parenquimatosas. La consolidación puede ser una atelectasia (obstructiva o no obstructiva), neumonía, contusión, infarto, tumor, etc. 
La ecografía no distingue la naturaleza de la consolidación, por lo que son otros criterios clínicos u otras pruebas complementarias los que orientarán el diagnóstico. No obstante, empiezan a aparecer trabajos que tratan de encontrar criterios discriminativos entre unas y otras. (Bustiet 2017)

\section{Neumotórax}

La detección de neumotórax es especialmente importante en el traumatismo torácico, el baro trauma asociado a la ventilación mecánica, tras la cateterización venosa central yugular o subclavia, y en pacientes a los que se va a trasladar en medios aéreos. La ecografía es muy sensible para el diagnóstico del neumotórax incluso de pequeño tamaño (ocultos en la radiografía de tórax).

Diferentes estudios la cifran entre un $90-100 \%$. Existen varios signos ecográficos. El primero es la ausencia de) deslizamiento pulmonar, ya que la pleura visceral pierde el contacto con la pleura parietal. En el modo M se pierde la apariencia de orilla de playa (con arena y mar) y solo se visualizan líneas horizontales paralelas, imagen conocida como el signo de la estratosfera o código de barras. No obstante, la falta de deslizamiento pulmonar puede producirse en otras enfermedades y circunstancias, como las adherencias pleurales, la intubación bronquial selectiva y la contusión, la consolidación y la atelectasia pulmonares. (Bustiet 2017)

Esta falta de especificidad hace que la decisión de realizar un tratamiento des compresivo inmediato basado exclusivamente en este signo dependa de las circunstancias clínicas del paciente. En el caso de inestabilidad hemodinámica (incluida la parada cardiocirculatoria), se optaría por la colocación de un drenaje. En el caso de que no existiera compromiso vital urgente, sería recomendable la realización de otra técnica de imagen. La presencia de líneas B nos permite 
descartar un neumotórax, ya que implica la aposición de ambas pleuras, lo que permite que se forme el artefacto.

Por último, existe un signo específico que es el hallazgo del denominado) punto pulmonar (lung point) en modo M. El mismo, se caracteriza porque se produce una sucesión de imágenes normales (arenosas) durante la inspiración y anormales (líneas horizontales) durante la espiración, y se corresponde con el punto del tórax donde, en inspiración, el pulmón) toca o alcanza a la pared torácica en el seno de un neumotórax no masivo. Derrame pleural Mediante la aplicación de transductores lineales directamente sobre el tórax, el derrame pleural se visualiza como un espacio libre de ecos (imagen anecoica negra) entre la pleura parietal y la visceral. (Bustiet 2017)

El segundo signo definitorio procede de la imagen en modo $\mathrm{M}$ a través del derrame, en el que se aprecian variaciones del espacio inter pleural con el ciclo respiratorio, que disminuyen con la inspiración (o la insuflación del respirador). Es lo que se denomina signo del sinusoide. Se puede acompañar de atelectasias compresivas en derrames cuantiosos, que se identifican como imágenes móviles de aspecto de medusa o lengua.

También es frecuente detectar derrames pleurales con transductores sectoriales de $3,5 \mathrm{MHz}$ que utilizan como ventana el abdomen, donde se observaría el líquido hipo ecogénico por encima del diafragma, visualización del interior del tórax a través de la colección y la inversión del diafragma si existieran grandes cantidades de líquido. De acuerdo con la apariencia ecográfica, el derrame pleural se clasifica en los siguientes tipos:

- Simple: totalmente anecóico. 
- Complejo no tabicado (sin septos): si existe material ecogénico en el seno de un derrame anecóico, generalmente puntiforme.

- Complejo tabicado (septado): si el material ecogénico tiene forma de filamentos o tabiques.

- Ecogénico difuso: por su apariencia con ecogenicidad aumentada homogéneamente, que se corresponde con la presencia de tejido desvitalizado, proteínas, fibrina y sangre. Aunque la clasificación de un derrame en exudado o trasudado es a veces difícil, incluso con criterios de laboratorio, la distinción es útil en términos de actitud diagnóstico-terapéutica. Las características del derrame en la ecografía pueden ayudar a diferenciar uno de otro. (Bustiet 2017)

En general, los trasudados son anecóicos, pero un derrame anecóico puede ser cualquiera de los dos. Sin embargo, un derrame complejo (tabicado o no) y uno ecogénico difusamente son siempre exudados. Estos últimos se corresponden habitualmente con hemo tórax o empiemas.

\section{APLICACIONES CLÍNICAS}

La ecografía pulmonar, aislada o combinada con otras técnicas ecográficas (ecocardiografía, ecografía vascular) se emplea actualmente en las siguientes situaciones clínicas. Algunas de ellas se han consolidado en la práctica clínica y otras están en fase de investigación y requieren más estudios para confirmar su validez y su utilidad.

Diagnóstico de la insuficiencia respiratoria aguda, de acuerdo con un protocolo al que han denominado Bedside Lung Ultrasound in Emergency (BLUE), el grupo de Lichtenstein ha alcanzado una precisión diagnóstica del 90,5\% sobre 260 pacientes ingresados en una unidad de 
cuidados intensivos por insuficiencia respiratoria aguda. Este protocolo consiste en la determinación de una serie de) patrones ecográficos. (Bustiet 2017)

Estos patrones se basan en la combinación del análisis del sistema venoso junto con la presencia o la ausencia de los siguientes signos: deslizamiento pleural, líneas A o B y derrame o consolidación. El diagnóstico diferencial incluyó las entidades más frecuentes (el 97,5\% de todos los casos), que fueron asma o agudización de la enfermedad pulmonar obstructiva crónica, edema de pulmón, embolia pulmonar, neumotórax y neumonía. Junto con la elevada exactitud diagnóstica, los autores destacan la precocidad en obtener un diagnóstico definitivo, que en este tipo de enfermos es de vital importancia. Además de este protocolo global, la ecografía se ha utilizado para el diagnóstico de entidades concretas en el ámbito de las urgencias, tales como:

- La neumonía radio oculta y la embolia pulmonar periférica. En pacientes en ventilación mecánica ha puesto de manifiesto abscesos en el seno de neumonías con respuesta desfavorable al tratamiento.

- Realización de técnicas procedimientos Tora cocentesis y drenaje pleural: la evacuación de derrames con fines diagnósticos o terapéuticos fue uno de los primeros usos de la ecografía torácica. (Bustiet 2017)

A través de estos diagnósticos pudo ser comprobado el aumento en la seguridad de la punción que proporcionaban la correcta y precisa localización y extensión del derrame. En pacientes en ventilación mecánica fue comprobado que reduce la incidencia de complicaciones, y se ha referido una tasa de neumotórax de tan solo el 1,3\%. Intubación traqueal: la ecografía pulmonar permite el diagnóstico de la intubación bronquial selectiva, ya que el pulmón no ventilado mostrará ausencia del signo de deslizamiento pulmonar. 


\section{BENEFICIOS QUE BRINDA LA ECOGRAFÍA DE TÓRAX AL DIAGNÓSTICO DE PATOLOGÍA}

\section{PULMONAR}

Las imágenes ecográficas del tórax, ya sea normal o en presencia de patología, vienen determinadas por la diferente impedancia acústica de los tejidos que lo forman (tejidos blandos, hueso, pleura, aire), que va a permitir identificar algunas estructuras anatómicas y, en otros casos, produce artefactos. La ausencia o el incremento del número de estos artefactos pueden representar signos ecográficos característicos de algunas patologías. La pared torácica aparece como una serie de capas de tejidos blandos de distinta ecogenicidad, la más superficial corresponde a la piel, la cual se visualiza como una capa ecogénica de 1 a $3 \mathrm{~mm}$ de espesor. (Bustiet 2017)

Inmediatamente inferiores, se identifican la grasa subcutánea y los músculos intercostales, éstos últimos visibles como múltiples estrías ecogénicas sobre una base hipoecoica. Más en profundidad, las costillas se observan, con la sonda ecográfica en posición longitudinal, como estructuras curvilíneas hiper ecoicas con sombra acústica posterior, producida por la absorción de la mayoría de ultrasonidos por el hueso. Entre ellas, a unos $5 \mathrm{~mm}$ por debajo, puede visualizarse la línea pleural. Esta imagen longitudinal de las costillas superior e inferior, con su correspondiente sombra posterior característica, se ha descrito como el signo del murciélago. (Bustiet 2017) 
Figura $\mathbf{N}^{\circ}$ 2. Imagen ecográfica con sonda cónvex, en proyección longitudinal del tórax (sonda en posición vertical). Las costillas aparecen comOestructuras curvilíneas hiperecoicas con sombra acústica posterior.

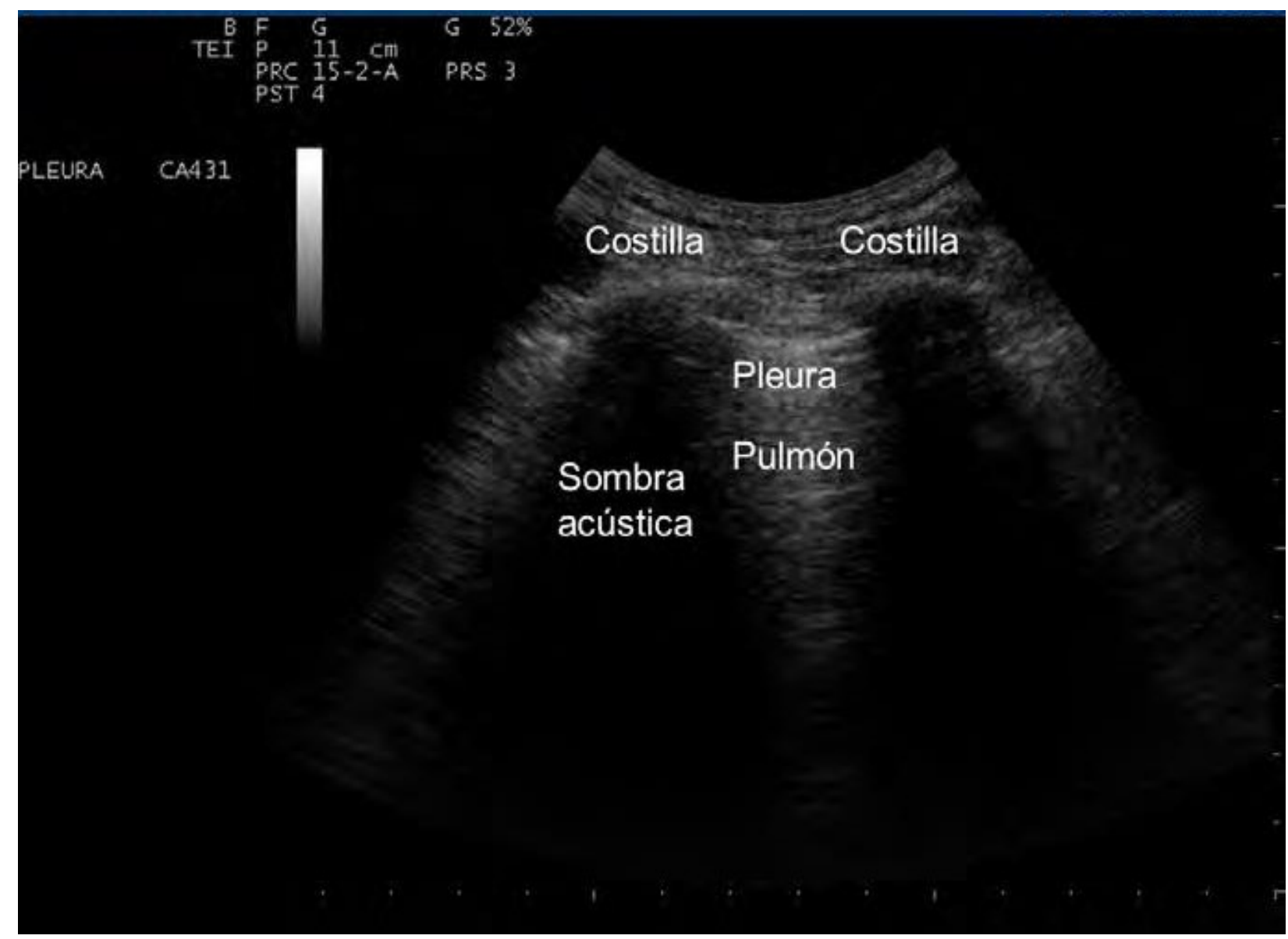

Fuente: (Bustiet 2017)

Cuando la exploración se da con una sonda de baja frecuencia en proyección oblicua (siguiendo la dirección del espacio intercostal), la pleura visceral y parietal aparecen como una línea hiper ecogénica única, de hasta $2-3 \mathrm{~mm}$ de grosor, que se mueve con la respiración, signo conocido como del deslizamiento pulmonar o lung sliding y que representa el movimiento de la pleura visceral contra la parietal. Con una sonda lineal de alta frecuencia, pueden distinguirse ambas hojas pleurales y, entre ellas, una mínima banda hipoecoica, que corresponde al espacio pleural. La pleura visceral suele visualizarse como una línea de mayor grosor que la parietal. 
Figura $\mathbf{N}^{\circ}$ 3. Imagen obtenida con sonda cónvex en proyección oblicua. Se aprecian la línea pleural y artefactos de reverberación (líneas A y B).

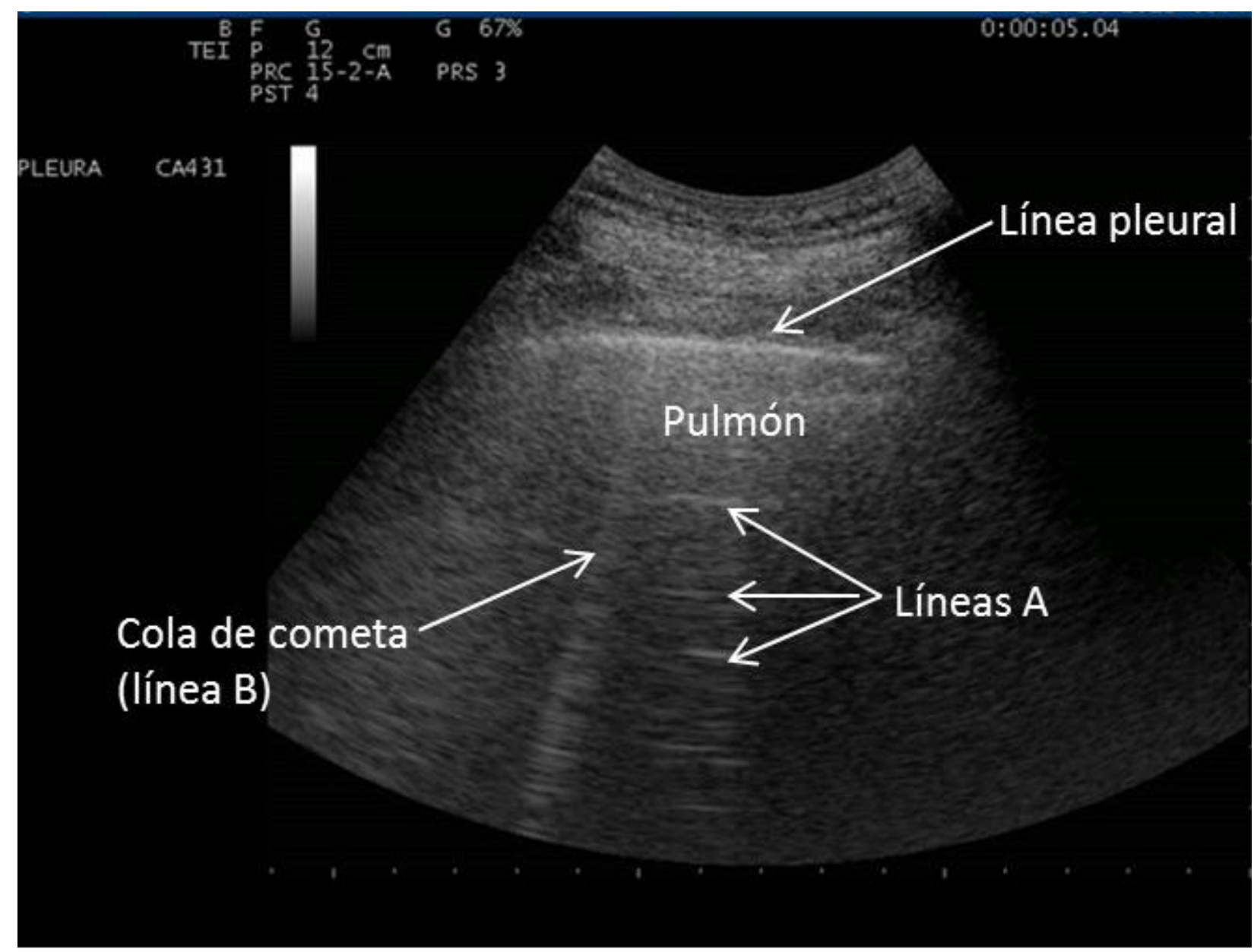

Fuente: (Bustiet 2017)

Por su parte, el diafragma puede verse a través de los espacios intercostales inferiores posteriores pero, en la mayoría de sujetos normales, el pulmón lo oculta durante la inspiración, junto a los órganos abdominales superiores. En caso de existir derrame pleural, éste actuaría como ventana ecogénica y permitiría su visión. Con el paciente en decúbito supino y el transductor a nivel subcostal, el diafragma se observa como una línea ecogénica de 1 ó $2 \mathrm{~mm}$ de espesor, inmediatamente por encima del hígado o bazo, de convexidad superior, que se mueve normalmente en dirección cráneo-caudal con la respiración. (Bustiet 2017) 
Figura $N^{\circ} 4$. Imagen ecográfica con sonda convex en región post erobasal de hemi tórax derecho (A): el diafragma no es visible porque está oculto por el parénquima pulmonar. En hemi tórax izquierdo (B): un pequeño derrame pleural actúa como ventana ecográfica y permite identificar el diafragma como una línea curva hiper ecogénica.

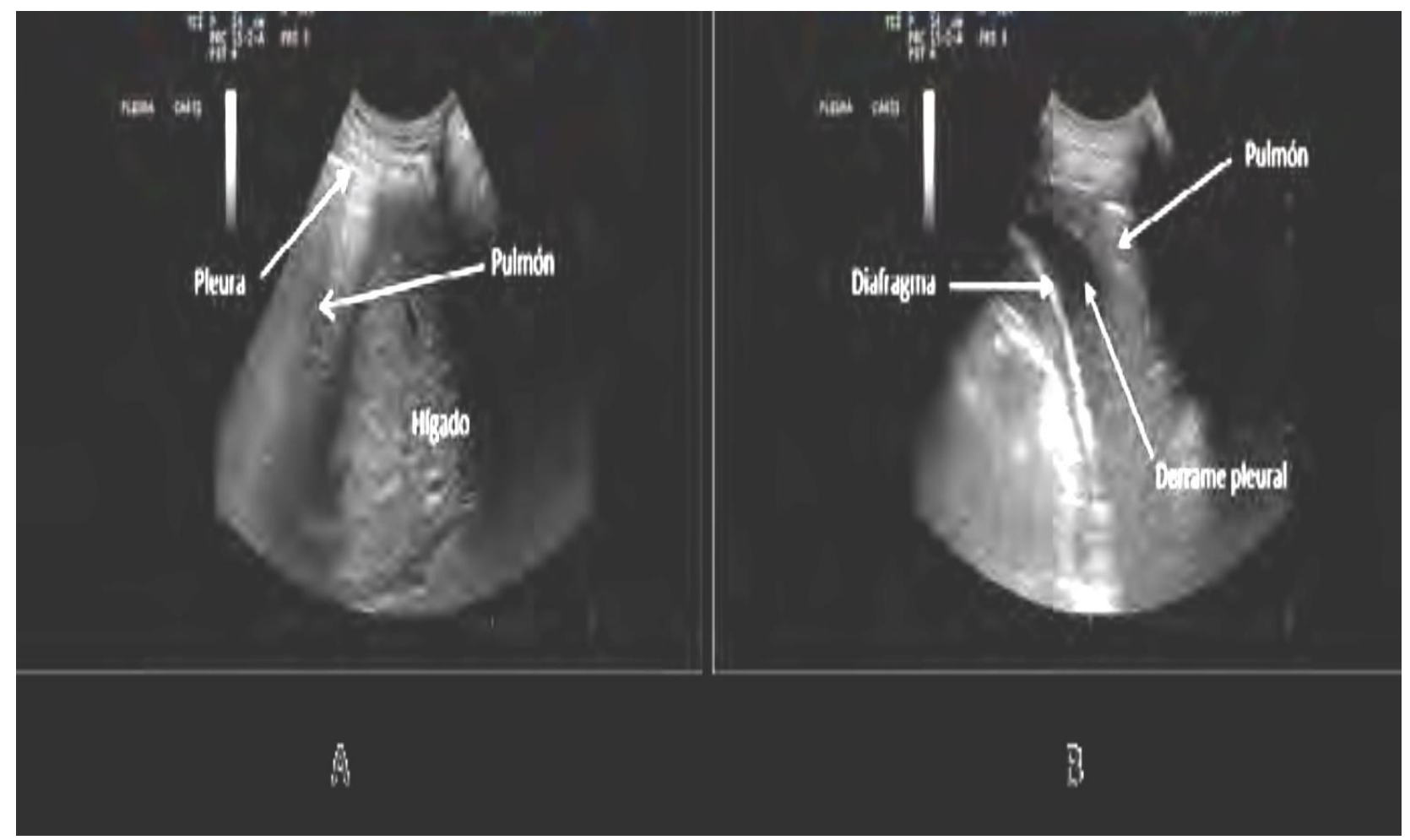

Fuente: (Bustiet 2017)

En la misma línea de explicación se presenta el parénquima pulmonar normal, el cual se sitúa por debajo de la línea pleural y es invisible por ecografía. Esto se debe a que los ultrasonidos son atenuados por el aire y a que, además, la gran diferencia de impedancia acústica entre la pleura y el pulmón hace que la mayoría de los ultrasonidos sean reflejados por la inter fase pleura-pulmón. Esta diferencia de impedancia acústica es responsable de dos artefactos característicos:

1. Artefactos de reverberación o líneas 
A: consisten en una serie de líneas hiper ecogénicas horizontales, por debajo de la línea pleural, paralelas y equi distantes una de otra. Representan la reverberación de los ultrasonidos reflejados por la superficie pleuro pulmonar. En adultos sanos, las líneas A suelen identificarse en los últimos espacios inter costales, por encima del diafragma. (Bustiet 2017)

2. Artefactos en cola de cometa o líneas

B: son también artefactos de reverberación y aparecen como imágenes verticales, producidas por múltiples ecos repetidos que simulan una cola de cometa. Se originan en la superficie pleural, se prolongan hasta la base de la pantalla, son móviles con la respiración y atraviesan y borran las líneas A. Las líneas B se deben a la reflexión del haz de ultrasonidos al encontrar un área intersticial engrosada, por la gran diferencia de impedancia acústica entre el aire y el edema o fibrosis existente en los septos inter lobulillares engrosados. Pueden verse en sujetos sanos, sobre todo en las bases pulmonares, pero más de 3 en un mismo campo se consideran anormales, como se verá más adelante, pueden apreciarse en diferentes entidades, como enfermedad pulmonar intersticial, insuficiencia cardíaca, etc. (Bustiet 2017) 
Figura $N^{\circ}$ 5. Pulmón normal líneas A y B.

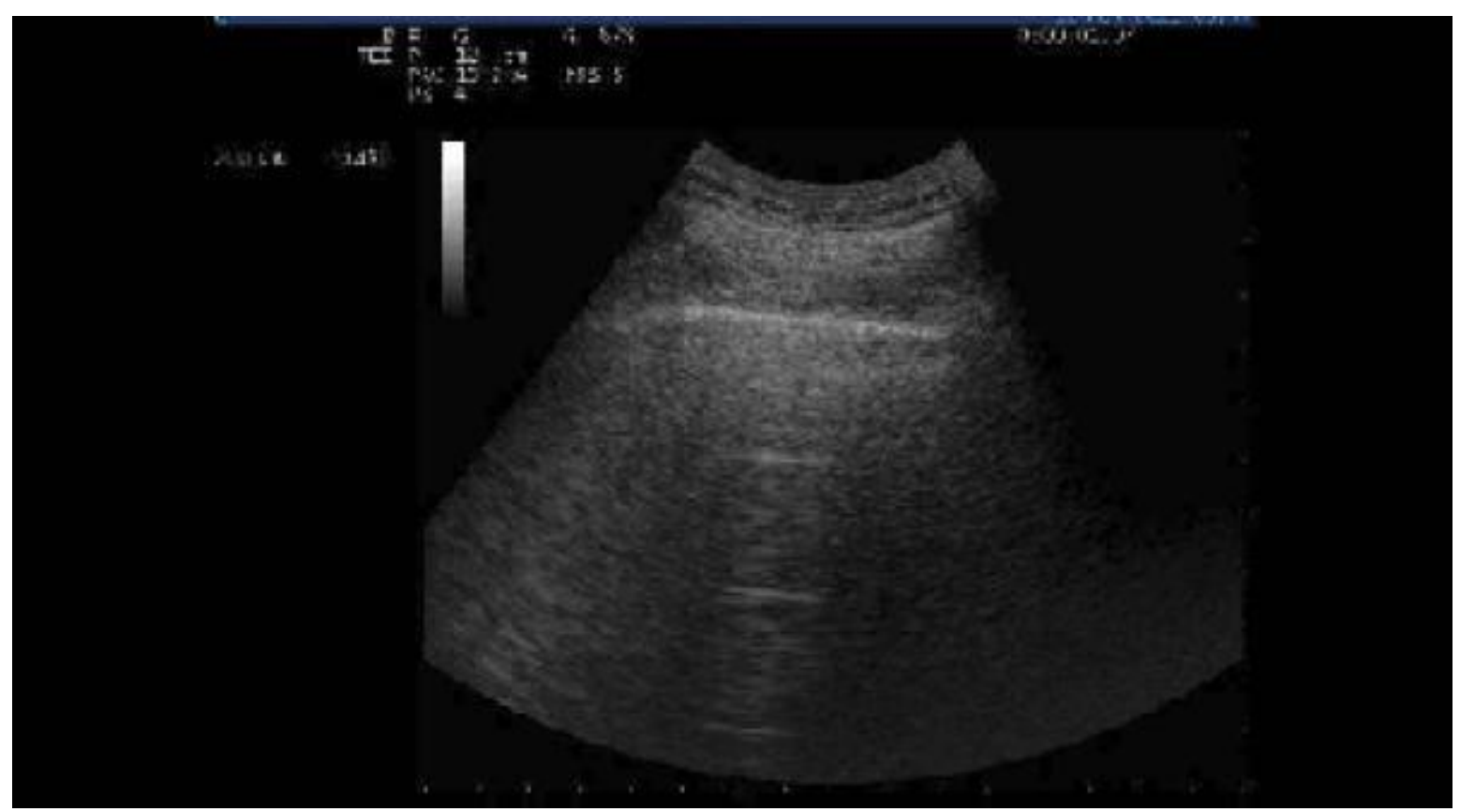

Fuente: (Bustiet 2017).

Los principales hallazgos que deben identificarse en el tórax normal son la línea pleural con el característico signo del deslizamiento y los artefactos representados por las líneas A y B.

\section{PRINCIPALES APLICACIONES Y SIGNOS ECOGRÁFICOS EN PATOLOGÍA TORÁCICA}

\section{Enfermedades de la pleura}

El papel de la ecografía en la evaluación de las enfermedades pleurales es ampliamente reconocido y, tradicionalmente, ha sido en esta patología donde la técnica ha tenido mayor difusión, en especial en la detección del derrame pleural y como guía para la toracocentesis. La ecografía puede ser útil, además, para definir las características del líquido pleural y orientar su etiología, dirigir otros procedimientos, como la biopsia pleural o la tora coscopia, localizar y guiar la punción de masas o engrosamientos pleurales, o en el diagnóstico del neumotórax. 


\section{Derrame pleural}

La ecografía es más sensible que la radiografía de tórax convencional, incluso en decúbito lateral, para detectar derrames pleurales, ya que es capaz de visualizar hasta $5 \mathrm{ml}$ de líquido, mientras que para verlos por radiografía deben acumularse al menos $150 \mathrm{ml}$ y cantidades superiores en la proyección anteroposterior en decúbito supino. El derrame pleural suele aparecer como un espacio, generalmente anecoico o hipo ecoico, que cambia de forma con la respiración, limitado inferiormente por el diafragma, en la superficie por la pared torácica y la pleura parietal, y, en profundidad, por la pleura visceral y la superficie pulmonar. Se han propuesto diversas ecuaciones para calcular por ecografía el volumen del derrame pleural, pero su utilidad en la práctica clínica es cuestionable.

\section{Engrosamiento pleural}

Suele visualizarse como un ensanchamiento hipo ecoico del espacio pleural, o banda hipoecoica gruesa superficial a la interfase pleura-pulmón. El engrosamiento puede ser secundario a pleuritis y, en este caso, se aprecia una interrupción de la línea pleural, con engrosamiento irregular de la pleura visceral. Las placas pleurales por exposición a asbesto se visualizan como engrosamientos hipo ecogénicos, con sombra acústica posterior, si están calcificada. El diagnóstico diferencial con el derrame pleural se basa en que el engrosamiento carece de movimiento y no cambia de morfología con la respiración, no presenta ecos o septos móviles internos y es característica la ausencia del signo del color líquido. 


\section{Tumores pleurales}

Las neoplasias pleurales benignas son raras, ya que representan, aproximadamente, un 5\% de los tumores pleurales e incluyen el tumor fibroso solitario, lipoma, condroma y neurinoma. Ecográficamente, suelen presentarse como lesiones bien delimitadas, moderadamente ecogénicas y pueden acompañarse de discreto derrame pleural. El tumor fibroso solitario de pleura, el más frecuente de las neoplasias benignas, suele presentar bordes bien definidos, aspecto hipo ecogénico o iso ecogénico y forma un ángulo obtuso con la pared torácica. El pulmón conserva su movilidad normal frente a la lesión, la cual puede evidenciar vascularización con el Doppler color. A veces, es difícil diferenciarlos de tumores de la pared torácica, que en muchas ocasiones pueden simular masas pleurales.

Los tumores pleurales malignos están representados por el mesotelioma, el linfoma y las metástasis. El mesotelioma aparece como un engrosamiento difuso irregular, a veces nodular, o como una masa hipo o isoecogénica, vascularizada, de bordes irregulares o polilobulados. Suele asociarse a derrame pleural importante. Las metástasis, la mayoría de carcinoma bronco génico, son los tumores malignos más frecuentes de la pleura. Normalmente, las metástasis se manifiestan como derrame pleural, ya que con frecuencia son de tamaño demasiado pequeño (menores de $1-2 \mathrm{~mm}$ ) como para detectarse por pruebas de imagen.

Cuando se identifican con ecografía, suelen presentarse como lesiones hipoecoicas, homogéneas, mayores de $5 \mathrm{~mm}$ en la pleura parietal, con bordes obtusos respecto a la pared torácica. La región más afectada es la pleura diafragmática y, casi siempre, se acompañan de extenso derrame pleural. Aunque en algunos casos las características ecográficas pueden sugerir la etiología 
neoplásica, el diagnóstico definitivo en la mayoría de ellos requiere confirmación cito histológica, siendo la ecografía una excelente herramienta para dirigir la toma de biopsias.

\section{Neumotórax}

Es una de las entidades en cuya evaluación inicial la ecografía ha tenido mayor difusión en los últimos años, sobre todo en pacientes graves o poli traumatizados, ingresados en unidades de cuidados intensivos, en los que la radiografía pierde mucha sensibilidad, al tener que realizarse en decúbito supino o de manera poco accesible. Los signos ecográficos de neumotórax incluyen la desaparición del signo del deslizamiento pulmonar y de las líneas B (la presencia de aire en el espacio pleural impide la visualización de la pleura visceral), aumento de artefactos de reverberación horizontales o líneas A y el signo del punto de pulmón (lung point), muy específico de neumotórax y que representa la transición entre el aire del neumotórax y el del pulmón normal ventilado.

La ecografía puede resultar de gran interés para el neumólogo para descartar neumotórax tras procedimientos intervencionistas, como punciones transtorácicas, en los que ha demostrado unos valores de sensibilidad superiores a los de la radiografía convencional y cercanos a los de la TC. En este sentido, puede evitar la realización habitual de Rx de tórax, tras la toma de biopsias trans bronquiales. El hidro neumotórax puede identificarse en ecografía por la presencia de artefactos de reverberación (líneas A) en el interior de un derrame pleural, que traducen la existencia de aire dentro del mismo. 


\section{Enfermedad pulmonar difusa (patología alveolo-intersticial)}

Existen múltiples procesos patológicos que afectan al pulmón, entre los que se incluyen las enfermedades intersticiales difusas y el edema pulmonar, pueden manifestarse como un síndrome alveolo-intersticial. La TC de alta resolución (TCAR) se considera la técnica de elección en el diagnóstico de las enfermedades pulmonares difusas. Sin embargo, algunos estudios indican que la ecografía puede tener un papel complementario en el diagnóstico, sobre todo cuando la radiografía o la TCAR no están disponibles o no son convenientes, como en gestantes.

Además, la ecografía puede ser de utilidad como método de cribado de afectación intersticial, por ejemplo en conectivo patías o en el seguimiento, evitando la sobreexposición a radiaciones que supone la realización de TC seriados. Por otra parte, mediante ecografía podría confirmarse la sospecha clínico-radiológica de un edema agudo de pulmón cardiogénico o de otra causa. Los hallazgos típicos radiológicos de las neumopatías intersticiales (engrosamiento septos interlobulillares sub pleurales y áreas en vidrio deslustrado) y del edema pulmonar (opacidades alveolares, vidrio deslustrado), se corresponden con artefactos ecográficos característicos.

El síndrome alveolo-intersticial se caracteriza, ecográficamente, por un aumento de líneas B o artefactos en cola de cometa, procedentes de la superficie pleural. Su origen, como se ha señalado antes, se atribuye a la diferencia de impedancia acústica entre el aire del pulmón y el engrosamiento de los septos sub pleurales. La sensibilidad de este hallazgo es elevada, pero es poco específico. Pueden verse también en bronquiolitis obliterante con neumonía organizada, neumonía y embolismo pulmonar 


\section{Enfermedad pulmonar localizada}

Mediante ecografía, pueden ser visualizadas las lesiones pulmonares periféricas que contacten con la pleura visceral. En caso de que se interponga entre ellas parénquima pulmonar normal, no serán visibles, debido a que, como se comentó previamente, la superficie pleuro pulmonar refleja los ultrasonidos por la diferencia de impedancia acústica.

Neumonía La ecografía, por las numerosas ventajas que aporta, es una herramienta muy útil para el diagnóstico de la neumonía, permite seguir la evolución de la enfermedad, sobre todo en pacientes más susceptibles a la radiación (niños y embarazadas) y detectar posibles complicaciones, como absceso de pulmón y derrame para neumónico complicado o empiema. Además, constituye la técnica de elección para dirigir la punción de cualquiera de ellos. Un reciente meta análisis, que ha evaluado estudios sobre la rentabilidad diagnóstica de la ecografía, encuentra una sensibilidad del 94\% y especificidad del $96 \%$ en el diagnóstico de neumonía, comparada con la Rx o la TC de tórax.

Trombo embolismo periférico e infarto pulmonar: La angio TC torácica es, actualmente, la técnica de elección en el diagnóstico del trombo embolismo pulmonar (TEP), pero la ecografía puede resultar de utilidad en pacientes críticos que, por su gravedad y problemas de movilización,

No son tributarios de una TC. Además, a pesar de que un resultado negativo no descarta el TEP, la ecografía puede jugar un papel importante en pacientes con sospecha del mismo en casos de embarazo, alergia a contrastes yodados o insuficiencia renal. La sensibilidad de la ecografía en el diagnóstico del TEP varía entre el 80\% a 94\%, y la especifidad del $84 \%$ a $92 \%$, según los estudios. 
Neoplasia: Como se ha señalado para otras patologías pulmonares, sólo podrán evaluarse por ecografía aquellas neoplasias que tengan contacto pleural. Aunque es difícil diferenciar lesiones benignas de tumores malignos, la ecografía puede ofrecer información sobre la naturaleza de la neoplasia y, además, servir de guía para la biopsia percutánea, por lo cual se considera una técnica muy valiosa en el estudio de las neoplasias pulmonares.

Patología de la pared torácica: La pared torácica está muy accesible a la ecografía, que permite evaluar diferentes patologías, como masas de tejidos blandos, adenopatías y lesiones óseas. Las primeras incluyen abscesos, lipomas y una amplia variedad de lesiones, la mayoría benignas. Las masas de pared torácica presentan una ecogenicidad muy variable y los hallazgos ecográficos son muy inespecíficos como para diferenciar entre varias etiologías, por lo que el potencial de la ecografía se limita a su detección, pudiendo servir, además, como ayuda en procedimientos intervencionistas.

Patología diafragmática El principal interés de la ecografía radica en la evaluación de la función del diafragma, pudiendo determinar la dirección y la amplitud del movimiento del mismo. Mediante la ecografía, se obtienen imágenes en tiempo real y, a diferencia de otras técnicas, como la fluoroscopia, se evita el uso de radiaciones ionizantes.

\section{Conclusiones}

La ecografía es una herramienta muy útil en neumología, por sus múltiples aplicaciones en diversas enfermedades torácicas. Ofrece numerosas ventajas, entre las que destacan la ausencia de radiaciones, portabilidad, bajo coste y presenta muy pocos inconvenientes. Esta técnica está llamada a ser el estetoscopio del neumólogo del siglo XXI. 
Este método diagnóstico, puede ser utilizado en el estudio de pacientes con patología quirúrgica de urgencia, ya que presenta una sensibilidad del $83,4 \%$ y una especificidad del $100 \%$ en su diagnóstico. Entre sus ventajas se destaca su accesibilidad, confiabilidad, no invasividad, de rápida realización y que no requiere de traslado en caso de contarse con equipo portátil y que permite un mejor seguimiento clínico en caso de duda o deseo de control evolutivo.

Entre sus desventajas se encuentra la de ser operador dependiente, por lo que se destaca la necesidad de contar con un adiestramiento básico, como para poder realizar el método, independientemente de la presencia de un médico especialista en diagnóstico por imágenes.

Investigadores coinciden que la ecografía se ha incorporado como una técnica primaria, lógica e inevitable de la evaluación y cuidado del paciente con patología traumática o no, ya que permite una rápida evaluación y un diagnóstico certero pudiendo tomarse una decisión quirúrgica o no de forma inmediata. Su elevada exactitud diagnóstica junto con diversas ventajas comparativas (disponibilidad, rapidez y accesibilidad) ha convertido a la ecografía en el método de diagnóstico más usado para la detección de líquido libre en la patología traumática.

En términos generales, la ecografía es una técnica de imagen ampliamente extendida en muchas especialidades. Los avances técnicos han hecho que los ecógrafos tengan cada vez mejor definición y mayor portabilidad. La neumología ha sido una de las especialidades médicas que ha incluido la ecografía como herramienta diagnóstica, pero hoy en día nadie duda de la necesidad de disponer de un ecógrafo en las unidades de técnicas neumológicas, debido a que puede actuar como herramienta, al lado de otras, como la punción transtorácica guiada con TAC o la punción transtorácica guiada con fluoroscopia. 
La portabilidad de estos aparatos permite realizar punciones en la propia habitación del paciente o incluso llevar el ecógrafo a zonas de pacientes críticos, cuando éste paciente no se pueda desplazar. Con la ecografía se evitan radiaciones ionizantes y puede repetirse cuantas veces sea necesario. Por último, con ella podemos ver lo que estamos haciendo en tiempo real, mientras que con la TAC lo vemos a posteriori, donde hemos realizado la punción.

\section{Bibliografía}

Arias, F. (2010). Paradigmas, diseño y enfoque de la Investigación Científica. España: Editorial: Luces.

Betroit, R. (2017). .Estudio y manejo de Patologías del Pulmón. Revista de Imagenología. American Jornal of Surgery., 32.

Bustiet, G. (2017). Beneficios de la Ecografía de Tórax en Patologías del Pulmón. Revsita Chilena de Neumonología Aplicada. Imagenología Actualizada. , 21.

Canott, P. (2015). Diagnósticos Pulmonares a través de Métodos Ecográficos. Revista Salud de Buenos Aires, Argentina, 15.

Cerrat, E. (2016). Ecografía de Tórax en el Diagnóstico de Patologías Pulmonares. Revista Vida y Salud de la Universidad de la Habana en Cuba., 11.

Dávila, N. (2012). Paradigmas de la Investigación Científica. Pereire, Colombia: Editorial: Las Brisas.

Garnerd, P. (2016). Estudios Diagnósticos a través de Técnicas Ecográficas Integrales. Revista de Neumonología Actualizada de la Universidad Autónoma de México, 18. 